\title{
Factors Driving Business Intelligence Culture
}

\author{
Rimvydas Skyrius, Igor Katin, Michail Kazimianec, \\ Svetlana Nemitko, Gediminas Rumšas, and \\ Raimundas Žilinskas \\ Vilnius University, Vilnius, Lithuania
}

\section{Rimvydas.skyrius@ef.vu.It; igor@getweb.It; kmichailas@gmail.com; Svetlana@nect.eu; gediminas.rumsas@ef.vu.It; raimundas.zilinskas@ef.vu.It}

\begin{abstract}
The field of business intelligence (BI), despite rapid technology advances, continues to feature inadequate levels of adoption. The attention of researchers is shifting towards human factors of BI adoption. The wide set of human factors influencing BI adoption contains elements of what we call BI culture - an overarching concept covering key managerial issues that come up in BI implementation. Research sources provide different sets of features pertaining to BI culture or related concepts - decision-making culture, analytical culture and others. The goal of this paper is to perform the rview of research and practical sources to examine driving forces of BI - data-driven approaches, BI agility, maturity and acceptance - to point out culture-related issues that support $\mathrm{BI}$ adoption and to suggest an emerging set of factors influencing BI culture.
\end{abstract}

Keywords: business intelligence, business intelligence adoption, business intelligence culture.

\section{Introduction}

The continuing growth of business intelligence (BI) applications and related issues keeps drawing significant attention of researchers and practitioners, and the variety of BI forms has introduced numerous innovations, definitions and redefinitions in areas relating to business intelligence. There have been suggestions to separate internal intelligence from external intelligence (Nash, 2010), business intelligence from business analytics, position decision support systems (DSS) as a part of BI (Kopačkova \& Skrobačkova, 2006) or BI as a part of decision support (Power, 2013); a rather detailed genealogy of the DSS field, including relations between DSS and BI, is presented in Arnott and Pervan (2014). This set of discussions has significantly widened the field of BI innovations and applications. However, regardless the quest of BI for advanced informing, the low levels of BI adoption are a fact confirmed by many academic and practical sources, and nu-

Material published as part of this publication, either on-line or in print, is copyrighted by the Informing Science Institute. Permission to make digital or paper copy of part or all of these works for personal or classroom use is granted without fee provided that the copies are not made or distributed for profit or commercial advantage AND that copies 1) bear this notice in full and 2) give the full citation on the first page. It is permissible to abstract these works so long as credit is given. To copy in all other cases or to republish or to post on a server or to redistribute to lists requires specific permission and payment of a fee. Contact Publisher@InformingScience.org to request redistribution permission. merous reasons have been named to understand the contradictory set of factors that drive BI success or failure. The technical foundations of BI are based on contemporary information technologies, and some researchers place IT as a dominating factor - e.g., Cao and Duang (2014) state that "business intelligence and business analytics are based on sophisticated information technologies". However, human factors of BI adoption

Editor: Eli Cohen

Submitted: January 15, 2016; Revised: March 15, 2016; Accepted: March 29, 2016 
have always been quoted by researchers as equally, if not more, important than technology factors. All steps of the BI cycle actually are performed by users, and BI technology is just an environment that accumulates and translates human intents without automating them - it does not create strategies, formulas or control signals.

Marchand, Kettinger, and Rollins (2001) have pointed to the importance of human factors like information behaviors and values. Fleisher (2008) has named creativity and original thinking among important human factors. Presthus (2014) has defined BI systems as socio-technical systems with equal importance between technical and human factors. Yeoh and Popovic (2015) have pointed out to user-oriented change management. Yoon, Ghosh, and Jeong (2014) have stressed social influence and learning climate as important human factors in adopting BI. Cohen and Levinthal (1990) have suggested an approach to merging managerial and informational factors into a feature named the absorptive capacity of an organization to receive and use external information, and stated that organizational absorptive capacity is not only the sum of individual capacities, but also the organized ability to exploit them. Carlo, Lyytinen, and Boland (2012) defined the existence of collective mindfulness as a set of mindful behaviors that create awareness and facilitate discovery in high risk environments.

The existence of a set of important human factors, pointed out in the above research as well as many other sources, suggests the presence of business intelligence culture as a collection of, attitudes, norms, and values which joins together the human traits of business intelligence. The principal challenges in implementing BI projects, pointed out in various research and professional sources (Gartner Research, 2008), are as well closely related to human factors, especially addressing BI culture aspects (see Table 1).

Table 1. Principal challenges in implementing BI projects (based on Gartner, 2008)

\begin{tabular}{|c|c|}
\hline Challenge & Relation to human factors \\
\hline $\begin{array}{l}\text { The value of BI project is not evident to the business. } \\
\text { The project is initiated by the top management, while } \\
\text { the other managers and employees, meant to be the } \\
\text { core users of BI system, do not fully realize the value } \\
\text { that BI might contribute for management and their } \\
\text { activities }\end{array}$ & $\begin{array}{l}\text { Users do not relate the BI project } \\
\text { to advanced informing and to } \\
\text { their actual needs. Projects are } \\
\text { isolated; there's no horizontal } \\
\text { community. }\end{array}$ \\
\hline $\begin{array}{l}\text { The MS Excel-dominated intelligence still prevails } \\
\text { in most companies, where the employees extract data } \\
\text { from various operational systems, manipulate it in } \\
\text { their personal intelligence space, and produce results } \\
\text { for their personal use. Such results are outside reach } \\
\text { for the rest of the organization, efforts are often du- } \\
\text { plicated, different users might produce contradicting } \\
\text { results that are hard to justify }\end{array}$ & $\begin{array}{l}\text { Fragmented and uncooperative } \\
\text { efforts, and no insight sharing in } \\
\text { place. }\end{array}$ \\
\hline
\end{tabular}




\begin{tabular}{|l|l|}
\hline $\begin{array}{l}\text { The attention given to data quality is still inadequate. } \\
\text { Systems that are based on incomplete, incorrect or } \\
\text { doubtful data cannot be used for real management } \\
\text { tasks. Such systems and their products experience } \\
\text { reduced trust from the users. }\end{array}$ & $\begin{array}{l}\text { Data quality might partly be relat- } \\
\text { Benvironments, especially ex- } \\
\text { ternal data, and limited data check } \\
\text { possibilities. Local sharing-based } \\
\text { "crowdsourcing" for data check- } \\
\text { ing might discover possible in- } \\
\text { consistencies by including more } \\
\text { people and their possibly related } \\
\text { data or information. Data govern- } \\
\text { ance and stewardship policy is } \\
\text { required. }\end{array}$ \\
\hline $\begin{array}{l}\text { A BI system is not a static reporting tool for lifetime } \\
\text { use. BI system has to evolve according to changing } \\
\text { business needs }\end{array}$ & $\begin{array}{l}\text { The agility of BI system and its } \\
\text { users as preparedness for change. }\end{array}$ \\
\hline $\begin{array}{l}\text { To reduce costs and time to operation, some busi- } \\
\text { nesses outsource the implementation of BI to an ex- } \\
\text { ternal entity. Often the result of such decision is a BI } \\
\text { system that is inflexible and of inferior quality }\end{array}$ & $\begin{array}{l}\text { Outsourced BI is a solution that } \\
\text { goes against the very nature of BI } \\
\text { as a sensitive strategic function. }\end{array}$ \\
\hline $\begin{array}{l}\text { In many organizations BI implementation faces a } \\
\text { lack of common understanding and shared meanings; } \\
\text { e.g., even a simple term like "income" might be } \\
\text { treated differently by employees of different depart- } \\
\text { ments }\end{array}$ & $\begin{array}{l}\text { Common understanding and } \\
\text { shared meanings very directly } \\
\text { relate to BI culture. }\end{array}$ \\
\hline $\begin{array}{l}\text { The last and largest mistake - an absence of con- } \\
\text { sistent, detailed and documented intelligence strate- } \\
\text { gy. Without this strategy BI development is just a set } \\
\text { of narrow unrelated projects that do not bring the } \\
\text { company closer to its strategic goals }\end{array}$ & $\begin{array}{l}\text { The absence of BI strategy may as } \\
\text { well be seen as an absence of BI } \\
\text { culture. }\end{array}$ \\
\hline
\end{tabular}

One of the most significant features of the above challenges is that many business organizations having undertaken BI projects did not give the human factors required attention and had ended up with a fragmented implementation of BI or not using the technology at all.

The analysis of recent research in the field of BI adoption has shown several driving forces considered important for the successful adoption of BI (this set is by no means exhaustive): datadriven approaches, BI agility, BI maturity, and BI acceptance. This paper aims at the analysis of the research sources regarding the above forces to subsequently point out the importance of the factors influencing BI culture and define a set of such factors. The method of this analysis is based on the elements of grounded theory, attempting to define objects of interest by analysis of research literature and practical sources. The assumed relations between BI driving forces, BI adoption and BI culture are shown in Figure 1. 


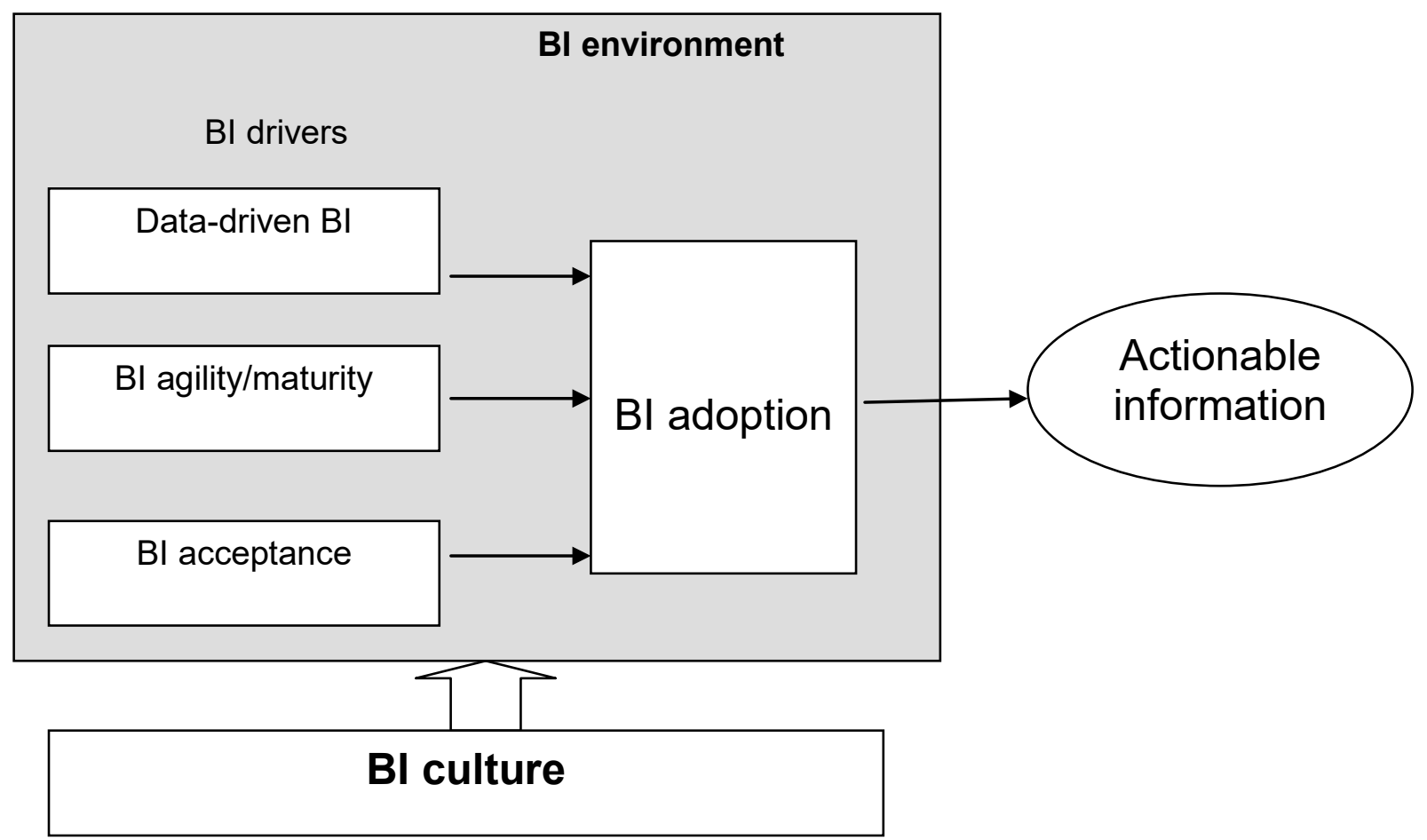

Figure 1. The relations between BI driving forces in a BI environment

In Figure 1, we make an assumption that the set of BI drivers in a BI environment in an organization influences BI adoption, which leads to actionable results of BI activities - actionable information that can be the ground for reliable actions, policies or other measures for executing a strategy. The influence of human factors on the forces driving BI adoption is joined here into a single component of BI culture, whose role for the above forces is discussed in the remaining part of this paper.

\section{Data-Driven and Needs-Driven Approaches}

One of the recent driving factors behind BI developments has emerged in the form of datadriven approaches that accentuate supply of information more than demand. These approaches have largely been initiated by the emergence of a phenomenon known as Big Data. The availability of huge and diverse sets of data has produced the idea that analysis of this data leads to discovery of useful and formerly unknown information supporting insight building and decision making. In published research and practical sources, two directions emerge here: one is that datadriven approaches consider the availability of data and analytical functions as important driving factor for BI; the other, although talking about data-driven, actually stresses the primary role of well-pointed questions presented to the data and the need to build certain insights.

McAfee and Brynjolfsson (2012) provide their arguments about required changes in what they call decision culture to reap the benefits of the data-driven approach. Although they call the subject of their discussion a data-driven approach, clearly there are features of an entirely different approach driven by information needs: ability to ask right questions, cross-functional cooperation between people involved in intelligence and decision making, the ability of data scientists to understand the language of business, to name a few. McAfee and Brynjolfsson argue that role of experience and intuition in decision making should be reduced to minimum, shifting the focus to data analysis and hard evidence. However, this approach works effectively when the required data and analysis tools are readily available, which is not always the case, especially in complex 
unstructured situations producing complex information needs, and this issue is a part of a larger issue of $\mathrm{BI}$ culture, regarding the roles of heuristics, intuition and communication.

A different point is expressed in S. Shah, Horne, and Capella (2012) where the decision makers have been separated into three groups by their willingness to use data and analysis. The extreme points are "unquestioning empiricists" who trust analysis over judgment, and "visceral decision makers" that exclusively use their gut, or intuition. The middle ground is called "informed skeptics" that manage to balance judgment and analysis, and are considered the best equipped group to make good decisions. S. Shah et al. call their approach "data-driven" as well, but their arguments tell that it is not so much the availability of data but the required skills and culture that create the value from intelligence activities. Jeanne Harris (2012) states, "analytical cultures are somewhat counter-intuitively extremely innovative and experimental in how they approach their business. So (such cultures) don't use data to justify a decision they've already made, they use it to gain new insights and understand their customers better"; this approach also carries more insight-driven momentum than data-driven. Presthus (2014) argues that BI will fail if the users disregard the data and rely only on intuition and judgment. Considering the current share of business information processes supported by IT, decision makers relying solely on intuition and judgment are not very common.

The term "data-driven" has a variety of meanings that range from pure impact of the availability of data to questions-based approaches that actually place the business question as a predecessor to using data. Cao and Duang talk (2014) about data-driven BI culture, where managerial decisions rely more on data-based insights. The same source provides the definition of data-driven culture from Kiron and Shockley (2011): according to them, a data-driven culture refers to "a pattern of behaviours and practices by a group of people who share a belief that having, understanding and using certain kinds of data and information plays a critical role in the success of their organisation". Redman (2013) provides a definition of data-driven activities that is actually mixed with needs-driven culture. Frick (2012), while discussing data-driven approach, drifts to the demand side, stating that part of the data-driven approach is "asking good questions". The study on datadriven business analytics by the Economist Intelligence Unit (The Virtuous Circle of Data, 2014) presents a staged approach that starts with technology implementation, with human issues and intelligence culture being the last; this approach has earlier been criticized by Tyson (2006). The definitions suggest that it is not exactly the data or its availability that is the key driving force in data-driven approach; rather, it is a combination of available data, technology, information and insights produced using this data, information behaviors that support sense making and insight building - all these factors are used together to create valuable intelligence for the organization. This point is supported in Overby (2014): "CMOs and marketing organizations need to hone their focus on both the business questions they need answered, and the decisions they want to inform."

The term "data-driven" itself might be somewhat misleading - raw data alone does not assist answering important business questions and proper insight building; this job is done by information that assists in building insights. The perils of the data-driven approach are the indulgence into extended analytics without clear relation to strategic goals or importance of insights, possibly leading to substantial use of resources for unclear returns. Some sources (e.g., Bollier 2010) have stated that the very point of looking at Big Data is "to identify patterns that create answers to questions you didn't even know to ask". This is a rather lucrative prospect for the data-driven approach that creates substantial expectations and may lead to illusions that all possible insights are in the data waiting to be discovered. Such approach does not necessarily guarantee business value. Intelligence is based on information and insights, not on data alone.

An alternative term would be an "insight-driven" BI that feeds on business questions, issues and needs to create required insights. Insight-driven approach may be seen as top-down - from a business perspective and its meaning to required insights, while data-driven approach may be 
seen as bottom-up - derived meanings without prior questions or expectations that valuable questions may emerge. Both approaches are feasible, but there has to be a clear understanding that the business needs are the deciding factor for choosing a certain approach or their mix. According to Marchand and Peppard (2013), BI users should avoid being bounded by easily accessible data and systems - they very likely might be based on rigid and outdated logic on how the business is run and processes are managed.

From the above sources we can conclude that for data-driven (or, rather, insight-driven) approaches to tap their potential, the availability of data alone is not sufficient; it has to be blended with a number of human factors such as motivation to ask well-pointed questions or a shared set of information, insights and values. There is a set of problems whose solutions might be supported by pure data-driven approaches (e.g., customer segmentation, alerts) as well, the rising interest in predictive and prescriptive analytics. However, we believe that insight-driven, or questionsdriven cases have a higher value potential, and even if this belief is currently based on assumptions only, we think it would properly deserve a separate research campaign.

\section{BI Agility}

The growing interest for the role of BI agility may be explained, at least in part, by growing interest for survival strategies. Teece (2007) has proposed a dynamic capabilities approach (DCA), where informing and flexibility play a center role. BI may create or support creation of dynamic assets (competences) that are unique and difficult to replicate (Teece, 2007). DCA applies both to sustainable competitive advantage or competitive survival (through the ability to adapt) and systems engineering through agile process models; so BI culture should cover both areas.

DCA essentially ties together BI and competitive advantage, or competitive survival strategies. The BI agility, based on flexible approaches, seems to be a definitive factor in enhancing dynamic capabilities. We have to note that DCA orientates BI towards a needs-based approach: datadriven approach sets its focus off-target by concentrating on possible data derivatives without clear business value; with needs-based approach, insights and sense are the focal point. According to Teece (2007), sustainable enterprise has the capacity to (1) sense and shape opportunities and threats, using a mix of external and internal intelligence, (2) to seize opportunities, and (3) to maintain competitiveness through enhancing, combining, protecting, and, when necessary, reconfiguring the business enterprise's intangible and tangible assets and using mostly internal intelligence. Following this approach, agile BI function, as one of the key intangible assets, should possess the required agility to reconfigure itself when necessary, with minimal costs or losses.

Among sources of research on BI, agility is mentioned as one of the key BI features. As Zimmer, Baars, and Kemper (2012) state, agility is central to dynamic environments. The competitive survival strategies, based on dynamic capabilities, start to dominate over competitive advantage strategies that are based on resource-based view, and this factor boosts the importance of agility.

Because BI systems not only are supposed to respond to changes, but to foresee them as well, the need for agility inevitably pushes them towards some degree of de-centrality. The BI development project in fact becomes a permanent process, and the BI state becomes a process as well. According to Zimmer et al, (2012) there needs to be a balance between discipline (rules, standards) and agility; it can be added that in search for greater agility, the coverage of rules and standards should be rather basic and clear.

According to Evelson (2011), while earlier-generation BI technologies have matured into industrial-strength solutions - function-rich, scalable, and robust - they have largely failed to address one simple, pragmatic business reality: the need for flexibility and agility. The next-generation technologies that can be categorized as "agile" refer to four major subcategories of agility: 
- $\quad$ automated, eliminating low-productivity manual tasks;

- pervasive, made available whenever decision makers need information;

- unified - compatible tools on a unified platform;

- limitless - without the limitations of previous technologies.

Describing the case of Disneyland Paris, Iafrate (2013) makes an important point: in intelligence applications, patience is required to see the potential value, but it is also important to get something useful running quickly, to get the culture changes started, and provide continuous value. In Disneyland Paris the models are constantly updated and become more accurate as the day/week progresses and the impact of unusual patterns can quickly be understood and adjustments made, adding to the flexibility and agility of BI system. This approach requires communication and sharing of information and insights.

\section{BI Maturity}

The concept of BI maturity leads to developing some kind of BI culture in the final phases. In various BI maturity models, the common feature of this culture is wide acceptance of BI throughout the organization and incorporating BI functions into everyday activity. All models of BI maturity lean towards ideal organization, automation of intelligence processes, and implementation of "once and for all" model of near-perfect BI. The mature stage is seen as an ideal state of BI, often with automation and optimization of key business activities in real time. In the authors' opinion, a dynamic BI field is difficult to mature; a much more realistic case would be the development of sustainable principal intelligence competencies. The important issue regarding BI maturity is that the users of BI have to make up their mind whether they are after insights and decisions that are optimal or just good enough, whose search requires less time and effort. Here we can quote Snowden and Boone (2007), "In a chaotic context, searching for right answers would be pointless", this quote serving as an argument for the agile nature of BI, discussed in more detail in the previous paragraph. A good point is provided by Evelson (2011), "while earliergeneration BI technologies have matured into industrial-strength solutions, they have largely failed to address one simple, pragmatic business reality: the need for flexibility and agility. As a result, centralized BI environments are anything but agile."

We can make an assumption that BI as a fluid and ever-changing phenomenon will never be mature in a sense of stability and routine; then the very idea of BI maturity may be questioned. The other option to define a concept of BI maturity might be a review of a separate BI technology or general IT trend for its maturity life cycle: some technologies emerge, gain adoption and experience, become established and routinized, or fade away and are replaced by other emerging technologies that are at the beginning of their maturity cycle.

One more issue with BI maturity is that in mature phases of most maturity models BI is expected to operate smoothly in close connection with MIS/ERP systems. In our opinion, hard coupling of MIS and BI reduces agility of BI and informing in general, because, although MIS/ERP and BI should work in tandem, the drive to make BI run as smooth as ERP systems are supposed to run is most likely to encounter problems - the mission of BI systems is much less structured, more sensitive to changing conditions and gives a larger role to human factors. Our approach to maturity is based on agility over optimization, regarding agility as a vital feature of contemporary business and its information environment, and largely connects with dynamic capabilities approach. 


\section{BI Acceptance}

In researching the issues of BI acceptance, Popovič, Hackney, Coelho, and Jaklič (2012) have related BI acceptance to what they have called an analytical decision-making culture (ADMC) that can help with overcoming the well-known tradeoff between reach and richness; a larger number of knowledge workers will use more complex BI systems and more comprehensive information.

Several hypotheses raised by Yoon et al. (2014) suggest that perceived social influence from referent others like coworkers or supervisors (hypothesis 6), or a learning climate (hypothesis 7), have a significant positive influence on individual intent to adopt BI application. This statement suggests that the existence of BI culture, of which supervisors, peers and learning climate clearly are part of, may be self-supportive.

Grublješič and Jaklič (2015) name organizational and information culture as important determinants of BI acceptance. Information culture includes information transparency, openness in reporting, and presentation of information on errors and failures. An interesting point in their research is that when asked about information culture, all interviewees in presented research have unanimously pointed this determinant as very important to $\mathrm{BI}$; however, a related question on organizational culture has fared much more modestly. This has raised an interesting side question on how much organizational culture and information culture are related, at least in the perception of the interviewees. Grublješič and Jaklič also point out to the importance of social influence if the demonstrable results of using BI positively influence professional image of BI users.

One more approach supporting the importance of human factors in BI adoption is Tyson's (2006) approach to order of procedures when implementing competitive intelligence: the implementation of an IT-based system should be the last stage of a buildup of competitive intelligence process; however, many companies start exactly from this implementation. While proper intelligence procedures and practices are not implemented in the organization, it is suggested to hold back the wide-range computerization of intelligence processes. To be precise, Tyson has addressed only the issues of competitive intelligence; however, competitive intelligence is the part of BI activities that is the least structured, most turbulent and uncertain, as compared to internal intelligence, and cultural issues are of prime importance in dealing with this uncertainty. This approach is supported in research by Infogroup, a consultancy (Olavsrud, 2014), that says early adopters of big data in marketing place insights before deployment, and Big data adoption is a process, executed in small steps - "you can't tackle big data in a day".

The common denominator of the current discussions is that over the last few years, one of the noticeable trends has been the emerging discussion on cultural issues in search for an overarching concept for human factors in the field of BI.

\section{The Definitions of BI Culture}

The term "intelligence culture", although not exactly obscure, is still somewhat vague and has been assigned multiple meanings. On the other hand, many sources agree that intelligence culture is closely related, or is a part of, the wider concept of organization culture. In discussing human factors of BI adoption, many sources refer to culture issues, assigning different contexts for culture. Grublješič and Jaklič (2015) stress information culture among important organizational determinants; in the same paper they also mention the culture of use of BI systems. Mulani (2013) defines issues-driven culture as an approach making data an asset to the business - right data at the right time and place, displayed in the right visual form, ensuring decision makers get access to intelligence, rather than just more information. The different aspects of BI culture issues and the suggested features of their context are presented in Table 2. 
Table 2. Features of various types of culture issues

\begin{tabular}{|c|c|c|}
\hline Source & Aspect of culture & Features \\
\hline $\begin{array}{l}\text { Grublješič and Jaklič } \\
(2015)\end{array}$ & BI culture & $\begin{array}{l}\text { Committed management support } \\
\text { Adequate organizational culture } \\
\text { Adequate information culture } \\
\text { Appropriate change management practices }\end{array}$ \\
\hline $\begin{array}{l}\text { Kiron and Shockley } \\
\text { (2011) }\end{array}$ & Data-oriented culture & $\begin{array}{l}\text { Analytics used as a strategic asset } \\
\text { Managerial support for analytics throughout the } \\
\text { organization } \\
\text { Insights are widely available to those who need } \\
\text { them }\end{array}$ \\
\hline $\begin{array}{l}\text { McAfee and } \\
\text { Brynjolfsson (2012) }\end{array}$ & $\begin{array}{l}\text { Decision making cul- } \\
\text { ture }\end{array}$ & $\begin{array}{l}\text { Leadership } \\
\text { Talent management } \\
\text { Technology } \\
\text { Decision making } \\
\text { Company culture }\end{array}$ \\
\hline Popovič et al (2012) & $\begin{array}{l}\text { Analytical decision- } \\
\text { making culture }\end{array}$ & $\begin{array}{l}\text { A decision making process exists and is under- } \\
\text { stood } \\
\text { Available information is considered regardless } \\
\text { of decision type } \\
\text { Such information is used for each decision pro- } \\
\text { cess } \\
\text { Shared use of BI functions and information }\end{array}$ \\
\hline Mulani (2013) & $\begin{array}{l}\text { Issues-driven ap- } \\
\text { proach }\end{array}$ & $\begin{array}{l}\text { Questions address the business issue, not the } \\
\text { data } \\
\text { Known needs of users } \\
\text { New tools and techniques for information inte- } \\
\text { gration and visualization }\end{array}$ \\
\hline Harris (2012) & Analytical culture & $\begin{array}{l}\text { Employees are good at creating questions and } \\
\text { working collaboratively with the data scientists }\end{array}$ \\
\hline Presthus (2014) & $\begin{array}{l}\text { Information infra- } \\
\text { structure }\end{array}$ & $\begin{array}{l}\text { Concentration on human factors of technology } \\
\text { adoption. } \\
\text { Simple and useful tools whose benefits (faster } \\
\text { data access, easier analytical functions) have } \\
\text { been communicated clearly from the beginning. } \\
\text { The IT platform stimulates use by being simple, } \\
\text { shared and open. } \\
\text { Self-reinforcing installed base - when users con- } \\
\text { tribute, the user base and the value of system } \\
\text { increases. } \\
\text { Improvements and additions are easy and per- } \\
\text { formed in-house. } \\
\text { Expandable with universal standards, preventing } \\
\text { eventual lock-in. }\end{array}$ \\
\hline
\end{tabular}


Summing up the presented culture issues, we may note that there are common features across all presented definitions of BI culture or related concepts. Most of them point to an environment that is inclusive and democratic; important information processes are understood and supported; the principal drive for leveraging BI potential comes from the users and management, not the availability of technology. This allows the more exact definition of BI culture: BI culture is part of organizational culture, and represents a set of norms, rules, attitudes, and values that acts as a catalyst in creating value by providing actionable insights to decision makers.

From the above analysis of forces driving BI and features of BI culture issues, several groups of factors that are most important in influencing BI culture and contribute most to the value created by $\mathrm{BI}$ investments are presented in the next section.

\section{Factors Influencing BI Culture}

\section{Cross-functional BI Activity}

The horizontal nature of BI function and the capability of BI to cross functional borders and join data and information buried in functional silos has been stressed by almost every source on BI adoption. Presthus (2014), using the title "information infrastructure", which is more likely to represent BI architecture, has stated that it unites technology, people, processes, communities, and tends to be self-organizing. Kiron and Shockley (2011) state that BI insights should be widely available to those who need them and present an example of BT (formerly British Telecom) that had linked its data silos to dramatically improve its customer service. Marchand, Kettinger, and Rollins (2001) have listed behaviors and values that enhance integrated information use, including transparency as an approach to deal with mistakes, errors, and failures positively, motivating organizational members to share important information. Evelson (2011), discussing BI agility, stresses pervasive BI nature as an important feature of agile BI culture.

\section{Sharing and Synergy of Virtual Teamwork}

Sharing is one of the essential features of BI culture supporting cross-functional information flows. For data-driven approaches, BI participants share resources, while for the needs-driven approaches they share the results. Uploading of information to be shared by a member of intelligence community can be motivated by former reception of useful information and mutuality. Marchand et al. (2001) state that information may be more freely shared among individuals or small teams than between departments in a company, thus supporting the point that these individuals or small teams actually constitute the intelligence community inside an organization. In a study on Big Data (Bollier, 2010) there's an example of Science Commons addressing the barriers to sharing information in scientific contexts, accelerating discovery and innovation. Sharing of intelligence information leads to integration of sense and skills to derive composite meanings from integrated information. It also creates anticipation of additional value by using additional expertise of other participators (Johnston, 2005, pp. 67-68). The importance of sharing is reflected in the data from IT Summit research in Table 3, showing the most often quoted functions of a BI system in use (out of same surveyed 69 business managers): 
Table 3. Most often quoted BI functions

\begin{tabular}{|r|c|}
\hline \multicolumn{1}{|c|}{ Functions provided by a BI system } & Share, $\%$ \\
\hline 1. Data security and access management & 93 \\
\hline 2. Real-time analysis & 86 \\
\hline 3. Data collection from many sources and systems & 84 \\
\hline 4. Possibility to share created reports and insights & 84 \\
\hline 5. Ad-hoc analytics for self-serving users & 77 \\
\hline 6. Data drill-down & 71 \\
\hline 7. Predictive analytics & 58 \\
\hline 8. Intuitive and clear user interface, requiring no training & 55 \\
\hline 9. Use of mobile devices & 46 \\
\hline 10. Data mining options & \\
\hline
\end{tabular}

We may note that functions supporting sharing of created reports and insights have been indicated by 84 percent of the surveyed business managers. The same research has shown that BI users who have practical experience in using BI systems rate sharing functions higher than non-users: $52 \%$ of users rated sharing options between 9 and 10 points (out of 10), as compared to $40 \%$ of nonusers for the same range of ratings.

\section{Record of Lessons and Experience}

The horizontal nature of BI function supports not only sharing of current information and insights, but of previous experience and lessons as well, including not only success stories, but errors, failures, mistakes and surprises, thus reinforcing trust among the members of BI community (Marchand et al 2001). Grublješič and Jaklič (2015) indicate availability of prior experience as one of the BI acceptance factors. Presthus (2014) has stated that when users contribute, the user base and the value of system increases. Discussing expertise management in an organization, R. Shah (2011) stresses the need to use social systems that aggregate available experience and develop competitive advantage through driving collective talent.

\section{Community}

The intelligence community - a set of people in an organization that execute intelligence, or, as Presthus (2014) has named it, the "installed base" - should be sustainable and self-reinforcing. It should comprise analysts and insight builders from key functional areas and with different analytical background; according to Harris (2012), data scientists should work collaboratively with business users that are good at asking business questions. To avoid becoming a counter-culture, this community should possess leadership and serve as change agents having the mandate of management to drive BI culture in an organization. This leadership, according to McAfee and Brynjolfsson (2012), should set goals, define success directions, and ask the right questions. Gradually the former shadow community should move to the key influencers, or middle managers (Hallikainen, Merisalo-Rantanen, Syvaniemi, \& Marjanovic, 2012). 


\section{Balance of Centralized and Decentralized BI Elements}

An important issue is the placement of BI function in an organization, deciding between centralized and decentralized approaches. Cohen and Levinthal (1990), discussing what they called the organization's absorptive capacity, had pointed out that an important feature of this absorptive capacity is information transfer across and within sub-units, and difficulty may emerge under conditions of rapid and uncertain technical change if an environment monitoring function is centralized. When external information of random nature is received, and it is not clear where in the firm or subunit a piece of outside knowledge is best applied, a centralized gatekeeper may not provide an effective link to the environment. Following these arguments, centralized approaches for BI are not agile enough and may effectively limit the potential of intelligence function; this point indirectly confirms the potential agility of decentralized and horizontal approaches to the distribution and flows of intelligence information as an important feature of intelligence culture. This point is also, if indirectly, supported by research performed by IT Summit, a consultancy that surveyed 69 business managers - actual BI users on the issues of BI adoption ("The Experience of Application of Business Intelligence Systems," 2015):

- when asked about dominating sources of decision support information, the largest share, or $68 \%$ of business managers pointed to analytical information produced by users themselves from BI systems;

- when asked about BI service latency, the largest share, or $72 \%$ of business managers, indicated that they may produce intelligence information (consolidated reports) by selfservice anytime.

\section{Technology Management}

The technology advances are probably the best seen signs of BI progress, yet their combination with under-developed human issues has led to disappointments and low BI acceptance. The role of technology, as seen from the discussions on BI culture, is to remove obstacles in utilizing the powers of IT and support the possible reengineering of information relations. Perhaps the dominating factor regarding the role of IT in developing intelligence culture is to provide simple tools and techniques, where the users may spend more time concentrating on gaining insights and solving problems than on mastering the technology. This point is supported in Presthus (2014), where a case of developing and reinforcing the BI community ("installed base") is presented; both attraction of initial base of users and its expansion are boosted by simple and easy-to-use IT capabilities. Barton and Court (2012) have presented cases where the use of a simple tool to deliver complex analytics substantially improved business processes. Yoon et al. (2014) have shown that complexity of BI applications negatively affects BI adoption. Similar results have been shown in Grublješič and Jaklič 2015). McAfee and Brynjolfsson (2012) note that there is a need for a skill set that might be new for most IT departments, e.g., to integrate structured and unstructured information.

\section{Conclusions}

The road to successful BI adoption has to include possible reengineering of information relations. By its nature BI technology is just a managerial tool to develop advanced informing and present decision information. It may be compared to an implant that has to be accepted and co-exist with people and processes in the organization, and this co-existence largely depends upon the state of "health" of the organization itself. User expectations towards IT are based more on advanced informing logic than on processing power and efficiency of IT. BI implementation requires substantial preparations and investment of effort into "soft" infrastructure - people, procedures, culture, motivation, skills, communication. BI culture may serve as a unifying term for human issues af- 
fecting BI adoption, and from the above discussions we may summarize the key factors influencing BI culture:

- Cross-functional BI activity: decentralized and horizontal nature without functional borders.

- Synergy of virtual teamwork: shared information, insights, mental models; the permeating and participative nature of BI community.

- Lessons as experience and proof of value; lessons from earlier success stories as well as failures, mistakes; decision-making best practices.

- Intelligence community that is motivated, sustainable and growing; self-reinforcing installed base - when users contribute, the user base and the value of system increases; role of change agents and BI leadership in an organization.

- Balance of centralized and decentralized BI conventions and functions; expandable with universal standards, preventing eventual lock-in.

- Technology management: simple and useful tools whose benefits (faster data access, easier analytical functions) have been communicated clearly from the beginning; the IT platform stimulates use by being simple, shared and open; easy feed, exchange and use of information and insights.

The above factors are more assumptions requiring further research in several directions, possibly including development of a model of relations between the factors, evaluation of their relative importance, specific requirements for information management, to name a few. However, we believe that the above set, although far from being exhaustive, reflects a trend in BI towards harmonization of human factors and alignment of efforts by establishing a flexible set of guidelines for sustainable BI developments.

\section{References}

Arnott, D., \& Pervan, G. (2014) A critical analysis of decision support systems research revisited: The rise of design science. Journal of Information Technology, 29, December 2014, 269-293.

Barton, D., \& Court, D. (2012). Make advance analytics work for you. Harvard Business Review, October, 79-83.

Bollier, D. (2010). The promise and peril of big data. Washington, DC: The Aspen Institute.

Carlo, J. L., Lyytinen, K., \& Boland, R., Jr. (2012). Dialectics of collective minding: Contradictory appropriations of information technology in a high-risk project. MIS Quarterly, 36(4), 1081-1108.

Cao, G., \& Duan Y. (2014). A path model linking business analytics, data-driven culture, and competitive advantage. Twenty Second European Conference on Information Systems (ECIS), Tel Aviv 2014.

Cohen, W. M., \& Levinthal, D. A. (1990). Absorptive capacity: A new perspective on learning and innovation. Administrative Science Quarterly, 35, 128-152.

Evelson, B. (2011). Buyer's guide: How agility will shape the future of business intelligence. Interactive. Retrieved from http://www.computerweekly.com/feature/Buyers-Guide-How-agility-will-shape-thefuture-of-business-intelligence

The experience of application of business intelligence systems in Lithuanian organizations. (2015). IT Summit survey report. February 2015.

Fleisher, C. S. (2008). Using open source data in developing competitive and marketing intelligence. European Journal of Marketing, 42 7/8), 852-866.

Frick W. (2014). An introduction to data-driven decisions for managers who don't like math. Harvard Business Review, May 19, 2014. 
Gartner Research (2008). Gartner reveals nine fatal flaws in business intelligence. Available online at: http://www.gartner.com/newsroom/id/774912

Grublješič, T., \& Jaklič J. (2015). Business intelligence acceptance: The prominence of organizational factors. Information Systems Management, 32, 299-315.

Hallikainen, P., Merisalo-Rantanen, H., Syvaniemi, A., \& Marjanovic, O. (2012). From Home-made to strategy-enabling business intelligence: The transformational journey of a retail organisation. Twentieth European Conference on Information Systems (ECIS), Barcelona 2014.

Harris, J. (2012). Building an analytical culture for big data. Retrieved from http://datainformed.com/jeanne-harris-how-to-create-analytical-culture/

Iafrate, F. (2013). Use case: Business intelligence "new generation" for a "zero latency" organization (when decisional \& operational BI are fully embedded). In P.-J. Benghozi, D. Krob, \& F. Rowe (Eds.), Digital enterprise design \& management. Berlin: Springer. Available online at: http://link.springer.com/chapter/10.1007\%2F978-3-642-37317-6_1

Johnston, R. (2005). Analytic culture in the US intelligence community. Washington, DC: Center for the Study of Intelligence, CIA.

Kiron, D., \& Shockley, R. (2011). Creating business value with analytics. MIT Sloan Management Review, September 15, 2011.

Kopačkova, H., \& Skrobačkova, M. (2006). Decision support systems or business intelligence: What can help in decision making? A Scientific Paper of the University of Pardubice. Available online at: http://dspace.upce.cz/bitstream/10195/32436/1/CL585.pdf

Marchand, D. A., Kettinger, W. J., \& Rollins, J. D. (2001). Information orientation: The link to business performance. New York, NY: Oxford University Press.

Marchand, D. A., \& Peppard, J. (2013). Why IT fumbles analytics. Harvard Business Review, JanauryFebruary 2013.

McAfee, A., \& Brynjolfsson, E. (2012). Big data: The management revolution. Harvard Business Review, October 2012, 61-68.

Mulani, N. (2013). Take an issues-driven approach to business intelligence. Available online at http://www.computerweekly.com/feature/Take-an-issues-driven-approach-to-business-intelligence

Nash, K. (2010). Using BI, BPM data to change business processes fast. Computerworld, June 17, 2010. Available online at: http://www.computerworld.com/s/article/9178207/Using_BI_BPM_Data_to_Change_Business_Proces ses Fast

Olavsrud, T. (2014). Businesses spending on big data marketing but not hiring for it. Available online at: http://www.cio.com/article/2379134/marketing/businesses-spending-on-big-data-marketing-but-nothiring-for-it.html

Overby, S. (2014). The CIO and CMO perspective on big data. Available online at: http://www.cio.com/article/2461403/cio-role/the-cio-and-cmo-perspective-on-big-data.html

Popovič, A., Hackney, R., Coelho, P. S., \& Jaklič, J. (2012). Towards business intelligence systems success: Effects of maturity and culture on analytical decision making. Decision Support Systems, 54, 729-739.

Power, D. (2013). Decision support, analytics, and business intelligence (2nd ed,). New York, NY: Business Expert Press, LLC.

Presthus, W. (2014). Breakfast at Tiffany's: The study of a successful business intelligence solution as an information infrastructure. Twenty Second European Conference on Information Systems (ECIS), Tel Aviv 2014. 
Redman, T. (2013). How to start thinking like a data scientist. Harvard Business Review, November 29, 2013.

Shah, R. (2011). Shifting the imperative from knowledge management to expertise management. Available online at: http://www.forbes.com/sites/rawnshah/2011/03/01/shifting-the-imperative-from-knowledgemanagement-to-expertise-management/

Shah, S., Horne, A., \& Capella, J. (2012). Good data won’t guarantee good decisions. Harvard Business Review, April 2012.

Snowden, D., \& Boone, M. (2007). A leader's framework for decision making. Harvard Business Review, November 2007, 69-76.

Teece, D. J. (2007). Explicating dynamic capabilities: The nature and microfoundations of (sustainable) enterprise performance. Strategic Management Journal, 28(13), 1319-1350.

Tyson, K. (2006). The complete guide to competitive intelligence. Chicago, IL: Leading Edge Publications.

The virtuous circle of data - Engaging employees in data and transforming your business. (2014). Teradata. The Economist Intelligence Unit.

Yeoh, W., \& Popovic, A. (2015). Extending the understanding of critical success factors for implementing business intelligence systems. Journal of the Association for Information Science and Technology. February 2015.

Yoon, T. E., Ghosh, B., \& Jeong, B.-K. (2014). User acceptance of business intelligence (BI) application: Technology, individual difference, social influence, and situational constraints. $47^{\text {th }}$ Hawaii International Conference on Systems Sciences, 3758-3766.

Zimmer, M., Baars, H., \& Kemper, H.-G. (2012). The impact of agility requirements on business intelligence architectures. $45^{\text {th }}$ Hawaii International Conference on Systems Sciences, 4189-4198.

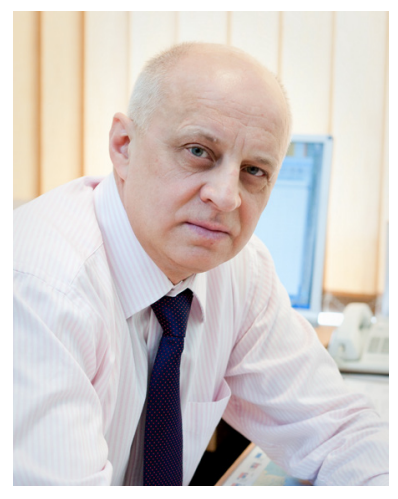

\section{Biographies}

Rimvydas Skyrius is a Professor and head of the Economic Informatics department at the University of Vilnius, Lithuania. He received his doctorate in Operations Research and Computer Applications from ASU-Moscow Institute in 1986, and his Master's degree from the University of Vilnius in 1978. His principal research areas are IT-based decision support in business and management, business intelligence and management information needs, and he has published a monograph, a number of articles and conference papers on the subject, as well as co-authored several textbooks in the field.

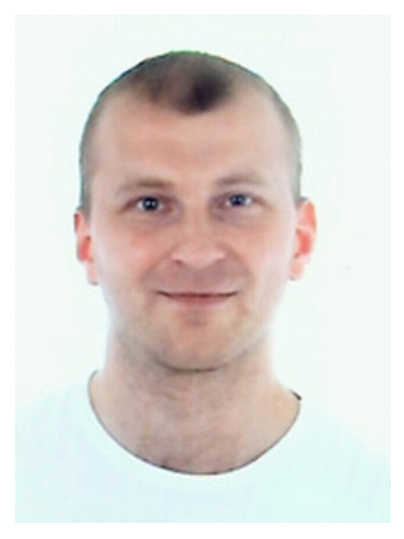

Igor Katin is a lecturer with Department of Economic Informatics, Faculty of Economics at Vilnius University, Lithuania. He gained his $\mathrm{PhD}$ from informatics engineering from Vilnius University, Institute of mathematics and informatics. His research and teaching interests include big data analytics, data mining, software systems and modeling, it technologies, game theory, local and global optimization. 


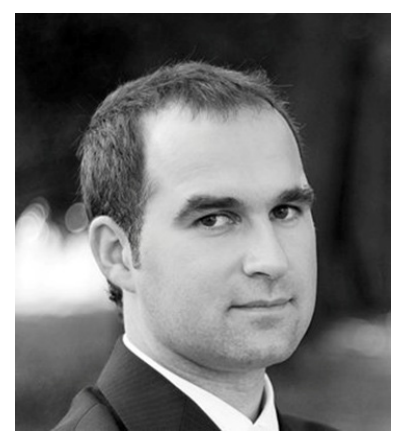

Michail Kazimianec is a lecturer with the Department of Economic Informatics, Faculty of Economics at Vilnius University, Lithuania. He received his $\mathrm{PhD}$ degree in Computer Science from Free University of Bozen-Bolzano, Italy. His current research and teaching interests include business intelligence automation technologies and application of predictive analytics as well as of big data analytics in business intelligence.

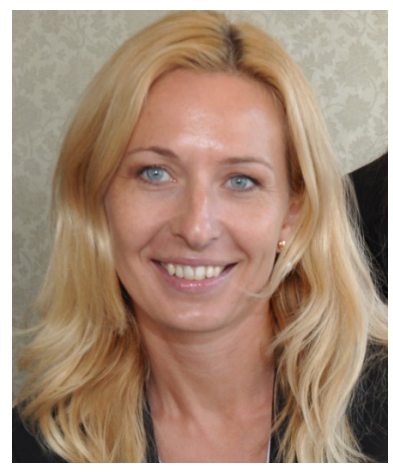

Svetlana Nemitko is a lecturer and a $\mathrm{PhD}$ student with the Department of Economic Informatics, Faculty of Economics at Vilnius University, Lithuania. Her research and teaching interests include business intelligence, analysis of BI business requirements and needs, business insight issues.

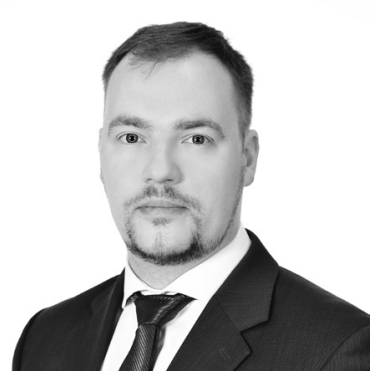

Gediminas Rumšas is a lecturer and a PhD student with the Department of Economic Informatics, Faculty of Economics at Vilnius University, Lithuania. His research and teaching interests include IT governance and management, business value delivery through IT.

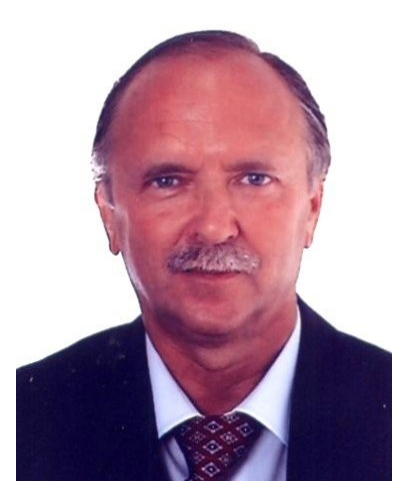

Raimundas Žilinskas is Associated Professor, doctor, with the Department of economic informatics, Faculty of Economics at Vilnius University, Lithuania. He gained his doctor degree from Vilnius University. His research and teaching interests include Business intelligence, Information systems strategies, Early warning systems. 